\title{
The Lighthouse Alarm and Locator trial - A pilot study
}

\author{
A. Melander-Wikman ${ }^{\mathrm{a}, *}$, M. Jansson ${ }^{\mathrm{b}}$, J. Hallberg ${ }^{\mathrm{c}}$, C. Mörtberg ${ }^{\mathrm{d}, \mathrm{e}}$ and G. Gard ${ }^{\mathrm{a}}$ \\ ${ }^{a}$ Department of Health Sciences, Luleå University of Technology, Luleå, Sweden \\ ${ }^{\mathrm{b}}$ Department of Business Administration and Social Sciences, Luleå University of Technology, Luleå, \\ Sweden \\ ${ }^{\mathrm{c}}$ Department of Computer Science and Electrical Engineering, Luleå University of Technology, Luleå, \\ Sweden \\ d Department of Informatics, University of Oslo, Oslo, Norway/University of Umeå, Sweden \\ ${ }^{\mathrm{e}}$ Department of Human Work Sciences, Luleå University of Technology, Luleå, Sweden
}

Received 3 June 2006

Revised /Accepted 27 November 2006

\begin{abstract}
An important factor for health is the possibility to be active and mobile. To make this possible various kinds of support are needed. Integrating geographical information systems technology and user experiences is important in the development of more user-friendly positioning devices. The Lighthouse Alarm and Locator trial aimed to test a new mobile alarm system with additional functionality such as positioning and monitoring of vital signs which can be used regardless of location (in hospital, at home). The system was tested by elderly persons from a pensioner organisation and home care personnel answered up on the alarms. After the tests qualitative interviews were performed with the two groups. The results showed that their experiences of the new mobile alarm system could be described in three main categories: to be supervised, to feel safe and to be mobile. These categories formed a theme: Positioning - an ethical dilemma. The clients' mobility was perceived to increase. The personnel did not think that positioning was ethical but the clients (elderly) did.
\end{abstract}

Keywords: Home care, mobility, positioning, safety alarm

\section{Introduction}

In Sweden the average lifetime is increasing, which not always means an increased health in the population but may increase the demand on rehabilitation services, in hospitals and particularly rehabilitation services in the client's homes [17]. An important factor for health is the possibility to be active and mobile. To make this possible various kinds of support are needed. A variety of technologies and services have been developed and implemented in order to reinforce elderly people's well being and conditions. However, the new technologies are not always adapted to prospective users' particular demands and needs in terms of functionality and usability.

Utility is the question of whether the functionality of a system or service can do what is needed and usability is the question of how well users can use that functionality [12]. Usability applies to all aspects of

\footnotetext{
*Address for correspondence: Anita Melander-Wikman, Luleå University of Technology, Department of Health Science, SE 97187 Luleå, Sweden. Tel.: +46920 491 000; E-mail: anita.melander-wikman@ltu.se.
} 
a system or service with which a person might interact, including installation and maintenance procedures. It is not a single one-dimensional property of user-interface. It is associated with dimensions such as learnability (to be easy to learn), efficiency (to be efficient to use), memorability (to be easy to remember), permit a low error rate so that users make few errors during the use of the system and satisfaction (pleasant to use) [12]. Usable is an adjective synonymous with "fit to use, functioning, operational, serviceable, and valid and working". Usability concerns fulfilment of functional requirements [15]. Within the MobiHealth project usability was defined according to ISO 9241-11: Guidance on Usability [1] as;

"the extent to which a product can be used by specified users to achieve specified goals with effectiveness, efficiency and satisfaction in a specified context of use".

Usability includes accessibility aspects as well as prerequisites for performing daily activities in the environment at target. It also includes subjective perceptions of how well the design of system or service enables functioning and well-being from the users' perspective [18].

Integrating geographical information systems (GIS) technology and user experiences is important in the development of more user-friendly positioning devices. Useful positioning devices need to be developed to support users in their daily tasks from risk assessment to prevention programmes. Institutions and home care organisations may benefit from the technological integration of GIS, the Web, handheld and mobile global positioning systems devices.

The aim of this paper is to explore the homecare clients (elderly people) and homecare personnel's opinions and experiences from a pilot study with positioning services in northern Sweden called the Lighthouse alarm and locator trial.

\section{The research context and setting}

Within the EU's “Information Society Technologies" Programme, the MobiHealth project was carried out during 2002 and 2003. The overall objective of the MobiHealth project was to develop new services and applications in the area of mobile health, promoting the use and deployment of GPRS and UMTS mobile services and technologies. The main task of MobiHealth was to deliver a flexible and dynamic service to patients and health care providers. Within the MobiHealth project 9 trials were performed within healthcare. The objective was to send physiological data from sensors in a Body Area Network (BAN) and via wireless transmission by GPRS and UMTS communication system to a monitor at a hospital or primary healthcare centre. The different pilots/trials ranged from sending data from an emergency situation, monitoring chronically ill patients by sending ECG from a person's home, monitoring complicated pregnancies or registering physical activity on persons with Rheumatoid Arthritis. All trials were heterogeneous in design in terms of number of patients (clients), the care givers/professionals involved and the purpose of using the MobiHealth system. In the project the partners used a participatory approach, i.e. the end-users were involved in the development and testing of the MobiHealth services. Two field pre-trials were conducted in order to create an interaction process between technicians and end-users. The purpose of each pre-trial was to gather information from the trial owners and to determine their experiences gathered from using the BAN. This experience was used as a basis for the technicians to further develop and design the BAN. Another purpose of the pre-trials was that the trial owners could get acquainted with, and test, the BANs and the user manual developed during the project. Throughout December 2003 and January 2004, the MobiHealth system prototype was tested in pre-trials in Spain, Germany, The Netherlands and Sweden. The purpose of these pre-trials was to evaluate the performance and user-friendliness of the equipment; and to provide data to the 


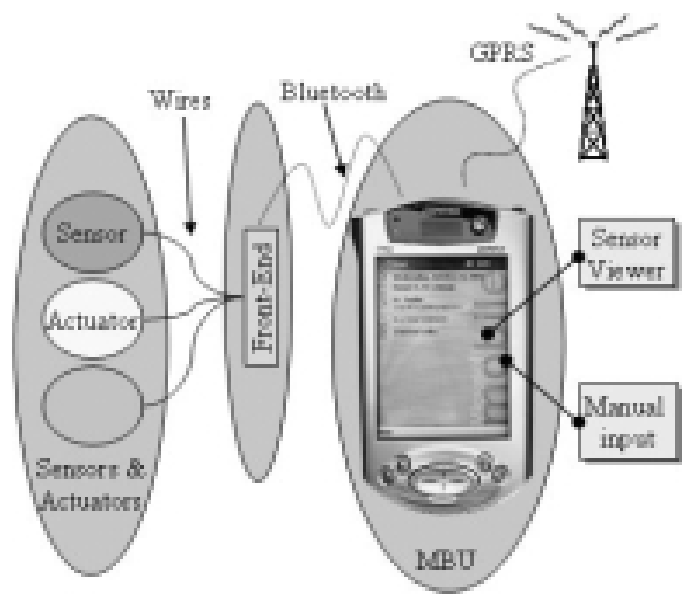

Fig. 1. The MobiHealth Body Area Network (BAN).

system providers for the final trials of the MobiHealth system in January and February 2004. The trials were developed in a step-wise process in interaction between researchers, technology developers and end-users. All the technologies were under development.

\subsection{The Lighthouse Alarm and Locator trial}

The trial in Sweden aimed to test this new mobile alarm system with additional functionality such as positioning and monitoring of vital signs which can be used regardless of location (in hospital, at home). The main expected benefit of using the MobiHealth BANs in this trial was to increase mobility and to allow clients (elderly) to live a more normal life than they did before. The current system in use does not allow the patients/clients any freedom related to mobility because of the limited range of transmitting the alarm by using radio waves. That implied that the client was trapped at home or in their room at the home care centre. By replacing the fixed alarm system with a mobile system the client (elderly) could move freely anywhere. Additionally positioning and vital signs were monitored. At the care resource centre the alarms were shown in a computer application. Positioning was used by a GPS receiver sending the positioning data via Bluetooth to a separate GPRS telephone, which showed the position in a map. When an alarm was sent from the elderly person the position could be presented both in a web based PC-application running in the homecare centre and in three additional mobile phones used by other personnel at the centre. It was possible to track down the elderly person's position by a visible map in the phone with regularly updated locations for both the elderly person and the searching personnel from the care centre.

The Lighthouse is a care resource centre located centrally in city in Northern Sweden. The Lighthouse creates support resources for the elderly in ordinary housing, provides direct and indirect support for relatives and those close to the client irrespective of whether they are staying in the Lighthouse or are in their own home, and may strengthen the resources aimed to secure the care and rehabilitation chain. Connected to the care centre is a reference group with representatives from different pensioners' organisation. This group is functioning as an advisory board to the centre.

Two BANs were available and the sensors used were activity (through a mobility sensor), marker (alarm button) and 3-lead ECG as well as manual input (Figs 1 and 2). The alarm went off either by pressing a button on the MBU, or when the drop-or inactivity signal (based on the mobility sensor) was 


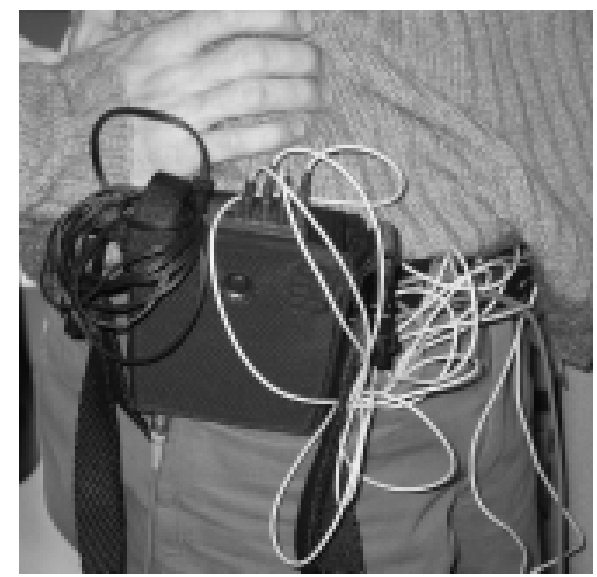

Fig. 2. The MobiHealth Front-End system.

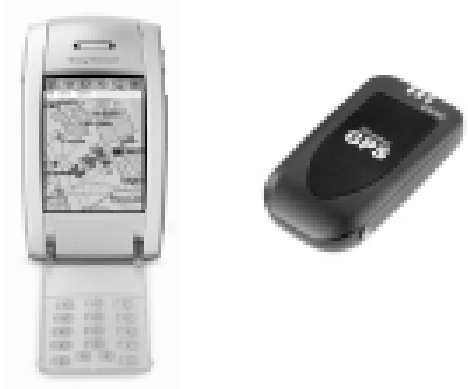

Fig. 3. The GPS receiver and the positioning application running on a mobile phone.

activated. The software application, PortiLab2 on the monitor at the Lighthouse care resource centre, displayed vital signs of the test persons (elderly persons), and the type of alarm (manual or drop) and the place on a map where the test person was located. This made it possible for the caregivers at the home care centre to answer up on the alarms correctly. In this trial the alarm and position was also sent via SMS to the caregivers.

\subsection{Positioning}

Positioning was used as an extra function for the Lighthouse trial and was developed as a separate system from the MobiHealth BAN. An Emtac GPS receiver was used to send satellite data via Bluetooth to a GPRS enabled mobile phone, a SonyEricsson P800 phone (see Fig. 3). While continuously obtaining new positions a map image with user preferred zoom and orientation was retrieved via GPRS from an online map service provided by Cartesia [3]. For storing and distributing position data between different users in the test, a location-aware platform was used [13]. With position data from others involved in the test the user had the option of selecting which positions to display on the map and then centre the map on these positions, which would in turn optimize the zoom and area factors of the map to fit the selected positions. To further increase the usability, the personnel itself was positioned and displayed as selectable options on the map, hence it was a simple manoeuvre to fit the personnel and the client 
(elderly person) on the same map image and then use the relative positions to easier navigate and finally locate the client (elderly person).

The positioning function was verified to work well together with the BAN. When an alarm was sent from the test person (elderly person), the position could be viewed both in a web-based PC-application running in the homecare centre and in the three additional mobile phones used by the other personnel at the centre. It was possible to track down the test person's (elderly person) position by walking with a visible map in the phone with regularly updated positions for both the client (elderly person) and the searching personnel from the homecare centre.

Since the positioning system was not integrated into the BAN it was not possible to utilize the alarm sensors in the BAN to activate the positioning, hence the positioning was left running at all times. With better integration it would have been possible to leave the positioning off while everything was fine and just activate it as the alarm was activated. This would save battery and possible also increase the sense of privacy.

\section{Methods}

Elderly persons from the pensioners' organisation and home care personnel were selected as test persons for the study. The home care personnel were told to reflect upon the use of the mobile technology from the clients' (elderly person's) perspective.

The outcomes reported in this paper are based on empirical data conducted by a focus group interview and a survey. Focus group interviews are used to explore how participants in a group, together, create a phenomenon [10]. The method is useful when the aim is to examine people's experiences and understandings of a phenomenon. Focus group interviews are conducted with a small number of people, four to six, who meet with the aim to discuss a given topic decided by a researcher [10]. In the survey a questionnaire was used, the MobiHealth Usability Questionnaire, that was developed in the MobiHealth project to measure different parameters of use of mobile technologies [7]. The parameters were derived from propositions concerning usability, empowerment, activity, mobility, participation and ethical considerations [8]. The result from the questionnaires were analysed according to the methodology (for a detailed description see [7]) developed in the MobiHealth project. The result stated in the questionnaires from each trial was gathered. Thereafter the commonality between trial as well as differences was analysed.

The narratives from the focus group interview was analysed through thematic content analysis [4]. The interview was read several times with the purpose in mind to get a feeling for the context. After that, text units where identified, still with the purpose as a guideline. The text units where formed into categories, which then formed three main categories. From the main categories a theme was crystallised like a read thread. The theme was Positioning - an ethical dilemma.

\subsection{Ethical considerations}

The range of the alarm system's coverage is a safety factor. Therefore an emergency might occur and go undetected. There was an ethical imperative to safeguard against this happening. Therefore a person was allocated to each test subject permanently during the trials to avoid this, and vulnerable patients were not addressed so as subjects, 5 members from the care centre's advisory board of pensioners were chosen (see subjects above). A further ethical consideration was the fact that, when positioning was used, a person might feel that they were being watched and interfered with. This and other questions were fulfilled adequately, including written consent. The committee of research ethics at Luleå University of Technology approved the study. 


\section{Results and discussion}

The analysis of the interviews and questionnaire resulted in three main categories: to be supervised, to feel safe and to be mobile. These three main categories formed a theme: Positioning - an ethical dilemma. The result will be presented and discussed under the same headings. The result showed that freedom of mobility seemed to increase. The personnel did not think that positioning was ethical but the clients (elderly) did.

\subsection{To be supervised}

In this pilot test the elderly persons involved were positive about the use of the new technology. They were positioned when they used the alarm equipment with the locator but they did not feel supervised and watched, However, the fact that they knew that they were positioned made them instead feel comfortable. The elderly persons were not doubtful about a general use. In the interviews the elderly persons expressed that they thought that it is right and proper to use the positioning device in the future when the prototype is fully developed to a product. One of them expressed: "It maybe would be possible to find old people if they disappeared from a pensioner's home". The results of the test showed how elderly persons thought a technology such as the prototype tested could improve their quality of life and life satisfaction. One test person (elderly) said that the fact that she could be found with the help of the positioning option if she got lost, made her feel safe. She said: "If I should need to use this I would be positive, that is Life Quality".

The elderly persons were asked to reflect on the use of positioning. In the interview they pointed out that it was important to discuss the service with relatives, personnel, and the (elderly) client before the positioning was decided. One test person (elderly) expressed this in the following way: "Who shall decide? Is it you yourself that can decide if you will have an alarm or not? Or is it someone else?" The interviewed were of the opinions that if an old person is able to decide, then s/he is the one to make the decision. But if s/he has got dementia e.g. it could be the care personnel at the care institution who should decide if positioning is needed. But it would still be best if a relative could be involved in the decision-making. Another test person (elderly) reflected upon that the technology was maybe a way for the municipality to save money, and was afraid that social contacts could be lost.

Elderly person's acceptance of information and communication technology (ICT) and telemedical solutions are increasing because they acquire technological skills and qualification to a higher degree, consequently, their use of Internet is increasing [2]. Elderly people have in fact seen a lot of technology come and go and they therefore often have a relaxed attitude to the possibilities that new technology offers [14]. Is this an explanation to the interviewed elderly person's positive attitude to mobile safety alarms with positioning? Another explanation could be that the elderly persons involved in this experiment/test were thinking of other elderly persons with limited functions using this new technology and not from there own needs and experience [14]. In the Swedish society there is a strong belief that ICT will secure growth and prosperity, as well a mean to keep alive the welfare state and its offers of good care and services for elderly citizens [6,11]. Thus, technological determinism dominates the Swedish society. A discourse that also governs at intervenes in peoples' stories like the conducted focus group interview.

The personnel also expressed, that the use of the mobile technology that was used in the test would increase the quality of life and satisfaction in their work, especially the locator function. On the other hand, when they reflected upon the use of the mobile technology from the clients' (elderly persons') perspective, the personnel discovered ethical dilemmas in using new technology, especially the positioning function. 
One care assistant expressed that "Some test persons feel safe when they are supervised; some test persons wonder a lot about it. Who is supervising? What kind of data can the personnel get?" They also discussed that the border between being supervised and expire safety is a hairbreadths difference. "You might easily feel overdriven." Foucault [5] discusses how different kinds of supervision and registrations are the modern society's way of disciplining people to become docile bodies. Disciplining technologies are used to get control and to create conformity, thus "the surveillance society" of today can be compared with Benthams Panopticon [5]. Panopticon is the ideal prison, formed as a circle with the cells in the outer circle and a surveillance tower in the middle. The aim with this design was to use only one guard to control and supervise all the prisoners. The prisoners are constantly aware of the guard's presence regardless if there is a person in the tower or not; the prisoner is subjected to surveillance without seeing anyone. The development of ICT with cameras and positioning systems creates "an electronic eye" that can be rationalising this. We are all leaving "electronic footprints" because of all new technology we are using. Every time we use a mobile phone or a credit card logs are left that are kept in different databases [19].

\subsection{To feel safe}

The technology used in the pilot test showed a person's location when s/he was walking out in the woods. Through the positioning the locator could easily find the person independently of where s/he was located. The interviewed elderly person's experience of the technologies possibility to locate her/him created a feeling of freedom and security. One interviewed pensioner said: "Now you can let next of kin go out in the forest, pick berries, because if they get lost you can find them through positioning." There was total consensus among the elderly persons, that this kind of technology was needed and safe. They were not afraid when using this new technology. "If it works- Positive to technology that can help". But one person said that "human values are important". Compared to the current used alarm system with a limited range of 10 meters this mobile alarm gave a better opportunity to be mobile and still feel safe. The care assistants (personnel) were critical about the safety of the system as GPS was not functioning indoors, so when the elderly persons were indoors they could not be located by the personnel. "It functions out door. Give signals for help". The sensors functioned $50 \%$ of the time. They did not think that the alarm was safe to use and it could not be used without risk. "More development is needed" was one comment from a care assistant.

We have already discussed how "the electronic eye" can discipline persons [5]. This discipline can create a feeling of safety. But the fact that one is supervised does not automatically promise that one will be safe. It demands that someone is there on the other side watching ready to act in case the person is in need of help. The architecture of the modern society has a close connection to control and supervision that is to discipline people in a particular way by technologies such as positioning services [5].

\subsection{To be mobile}

The test persons(elderly) found the prototype clumsy and awkward to wear with too long wires. The wires made it difficult to dress for outdoor activities. "It is clumsy. It limits the mobility. Should if possible be made smaller and more pliable". "In wintertime with outdoor clothing the freedom of mobility is highly restricted". When travelling the test persons thought that there were many things to remember to bring and they also said one had to be cautious when putting on the safety belt in the car because the sensors could come off from the sensor box. "Clumsy while getting in and out off the car". There was not a problem in driving the car while wearing the alarm equipment and this made the test 
persons feel free to leave their homes. This was in contradiction to the current alarm that, because of the limited range, made it impossible to go outside the house even to collect the morning paper and still feel safe.

The care assistant (personnel) and the nurse used a mobile telephone and software application as their technical devices. On the mobile telephone the map for locating persons was visible except when the test persons were indoors. They described that they could locate the elderly test persons during the test. "The GPS have functioned best, but the map could be more accurate". One care assistant (personnel) commented the design of the alarm and stated that "I have noticed how important it is for the test persons that the alarm equipment is discreet and do not make any sounds to others outside the home".

Mobility is a dimension of empowerment, which is prerequisite for elderly person's possibilities to participate in society. Participation is involvement in life situation [21]. Elderly persons do not want technical products that characterises them as old and is connected with sickness and dependence. Using a traditional safety alarm can decrease the elderly person's flexibility and hinder them to live a normal social life [16]. The result of this study of mobile safety alarm showed that the prototype tested made it possible for the test persons (elderly) to move around more and still feel independent and safe. The mobility was also limited in some situations by the design of the device. Perhaps this kind of mobile technology tested in this pilot can enable elderly persons to become more independent, self-determining and mobile. For the care assistants (personnel) and nurses the system also made it easier to find missing persons and therefore served as a decision support.

\subsection{Positioning - An ethical dilemma}

In analysing the findings a theme developed from the three categories To be supervised, To feel safe and To be mobile. This theme was "Positioning - an ethical dilemma". While the elderly persons did not identify any hinder or dilemmas in being supervised, the care assistants and nurse did. The care assistants and nurse who participated in this pilot test thought that it was right to use this kind of technology and proper to position people as a tool within healthcare but after reflecting upon it from the elderly person's perspective, they though it was unethical. Empowerment and aging can sometimes be a problem. Healthcare professionals not only must create prerequisites for empowerment they sometimes must take it away. Restricting freedom is always a dangerous step but sometimes it is best for all involved [20]. In this study the elderly persons seemed to be ready to offer the integrity loss that positioning is causing. Instead they felt they will get more freedom of movement and a feeling of safety. The elderly persons in this experiment reflected upon future use and visions about how the prototype would function as a fully developed product. They experienced limitations in mobility, limitations due to the design of the device.

The main task of MobiHealth was to deliver a flexible and dynamic service to patients (clients) and health care providers with a focus on optimal utility and usability. In this study usability includes accessibility aspects as well as subjective perceptions of how well the design of system or service enables functioning and well-being from the users perspective [18]. The results showed that all users could see a need for a mobile system and they had high expectations from the start. The system which was delivered and tested in field trials was not up to the expectations of the users. A lowering of expectation was noticed among the users (especially the elderly persons that acted as test persons), probably coming from a unrealistic belief at the start that the system delivered should be a fully developed, commercial system that was completely stable, which was not the case. Initial problems with technical support did not contribute to a feeling of confidence in the system; later on this support network improved and an environment of mutual cooperation towards development and integration created higher confidence. 
Despite this initial disappointment, by project end all users agreed that a product of the kind delivered in prototype form would be very useful, if made more stable.

A question to be asked is whether in the future it is realistic to use distance monitoring in a community. When this question was addressed to the telecom company that was one of the Swedish partners in the MobiHealth project, the answer was positive (personal communication Kjelleryd 2006-08-29). He said that the permanent safety alarm system already has thousands of clients as users and that there are already an organisation answering these safety alarm calls in Sweden. If mobile safety alarms are introduced the technology is constantly improving and the bandwidth needed is already there. If the monitoring means that the alarm is going off if something remarkable is happening then it is no problem taking care of this. The problems with wrong alarms are already there and staff are used to handle this so if a mobile alarm will cause wrong alarms this will be solved (ibid.). Our opinion is that more research must be done around reasons for wrong alarm and also in what situations persons are using safety alarms. The safety alarms should also be constructed to fit individually to different needs. A mobile safety alarm should not be answered up by a medical doctor as first receiving instance. The main thing is that the alarm is taken care of at once and if intensive care or medical care is needed the call will be rerouted (personal communication Kjelleryd 2006-08-29). This would be in line with how some elderly persons would like this service to be [9]. A remaining problem also confirmed by representatives from the telecom companies is the problem associated with with battery supply. The existing batteries need to be reloaded too often and this decreases the safety as you need to be close to a reloading device (personal communication Kjelleryd 2006-08-29). This knowledge needs to be taken in to account by the developers of safety alarm technology. Another problem is related to the presently available sensors (size, weight and reliability of the electrodes). This makes us think that concerning the safety alarms, the most important sensor is a drop sensor and not a sensor for registration of ECG. The main objective when using a safety alarm is getting a quick contact that can put your need forward to the right competence needed.

There was a close interaction between researchers, technology developers and end-users during the whole study. The subjects were members of an advisory board of elderly persons that the community uses to interact and communicate with concerning all kinds of questions in the community when opinions from an elderly forum are needed. The evaluation questionnaire underwent a process of iterations with agreement from all participants from the technical, medical and evaluation side, which led to a fine-tuning of the methodology; from a large number of respondents from different fields to fewer respondents, and from a set of detailed questionnaires and interviews, logbooks, field notes and diaries, to just questionnaires and limited interviews and field notes. This was carried out in very close cooperation with trial owners and technical partners, in weekly meetings throughout the project. The process could be called "a development by users-process" with participation from all parts and freedom to express ideas, beliefs and ethical considerations. The elderly persons that were research persons in this experiment reflected upon future use and visions about how it would be as a ready developed product. The experienced limitations in mobility that came from the design of the device were their contribution in the developing of the prototype.

\section{References}

[1] N. Bevan and R. Schoeffel, A proposed standard for consumer product usability, Proceedings of 1st International Conference on Universal Access in Human Computer Interaction (UAHCI), New Orleans, August 2001.

[2] R.L. Bratton and T.M. Short, Patient satisfaction with telemedicine: a comparison study of geriatric patients, Journal of Telemedicine and Telecare 7(6 supplement 2) (2002), 85-86. 
[3] Cartesia [www document] URL http://www.cartesia.se/ (September 2005).

[4] B. Downe-Wamboldt, Content analysis: method, applications and issues, Health Care for Women International 13 (1992), 313-321.

[5] M. Foucault, Discipline and Punish - The Birth of the Prison, Penguin Books Ltd., 1977.

[6] M. Jansson, C. Mörtberg and E. Berg, Old dreams, new means - an exploration of the paradoxes of new technologies. (Accepted by the Journal Gender, Work and Organization) (2006).

[7] A. Melander Wikman, M. Jansson and G. Gard, The MobiHealth Usability Evaluation Questionnaire, E-Health International 2(1) (2005), 9-14.

[8] A. Melander Wikman, M. Jansson, R. Herzog, D. Konstantas and T. Scully, Overall evaluation of the MobiHealth trials and services (D5.1) The MobiHealth project. Project Number: IST-2001-36006, www.mobihealth.org.

[9] A. Melander Wikman, Y. Fältholm and G. Gard, Safety versus Privacy-Elderly Persons Experiences of a Mobile Safety Alarm, 2006, (in manuscript to be submitted).

[10] D.L. Morgan, Focus Groups as Qualitative Research, Second Edition, Sage Publications, 1997.

[11] C. Mörtberg, Information Technology Politics: towards a feminist approach, in: Technology and Democracy: Gender, Technology and Politics in Transition? I. Moser and G.H. Aas, eds, Proceedings from Workshop 4, TMV Skriftserie, nr. 29, Centre for Technology and Culture, University of Oslo, 1997, pp. 23-37.

[12] J. Nielsen, Usability Engineering, New York: Academic Press, Orlando, 1993.

[13] J. Nord, K. Synnes and P. Parnes, An Architecture for Location Aware Applications, Proceedings of HICSS-35, Big Island, Hawaii, USA, 2002.

[14] B. Östlund, Gammal är äldst - om teknik i äldre människors liv. (Old is the oldest - about technology in elderly persons' life, Authors translation.) Linköping Studies in Arts and Science No 129, Tema, Linköping University, 1995.

[15] Oxford Popular Dictionary and Thesaurus, Oxford University Press, 1998.

[16] P.H.F. Peeters, Design criteria for an automatic safety-alarm system for elderly, Technology and Health Care 8 (2000), $81-91$.

[17] SCB (2006) Population in thousands 12.31.2005 and projection 2006-2050. [www.document] URL http://scb.se/templates (2006-11-05).

[18] E. Steinfeld and G.S. Danford, eds, Eabling Environments. Measuring the impact of Environment on Disability and Rehabilitation, Kluwer Academic, New York, 1999.

[19] P. Ström, Övervakad: Elektroniska Fotspår och Snokarsamhället. (Supervised: Electronic Footprints and the snooping society, Authors translation). Liber AB, 2003.

[20] I. Stuart-Hamilton, Ageing and empowerment: Questions and dilemmas, in: Empowerment Through Reflection - The Narratives of Healthcare Professionals, T. Ghaye, D. Gillespie and S. Lillyman, eds, Mark Allan Publishing Ltd., 2000.

[21] World Health Organization, International Classification of Functioning, Disability and Health: ICF: WHO, 2001. 
Copyright of Technology \& Health Care is the property of IOS Press and its content may not be copied or emailed to multiple sites or posted to a listserv without the copyright holder's express written permission. However, users may print, download, or email articles for individual use. 